Revista de la red interuniversitaria de estudios sobre las literaturas rioplatenses contemporáneas en Francia

16 | 2017

Esnobismos

\title{
El dandismo y la elegancia como invisibilidad de la apariencia
}

\section{Edgardo Cozarinsky}

\section{OpenEdition}

\section{Journals}

Electronic version

URL: http://journals.openedition.org/lirico/3577

DOI: 10.4000/lirico.3577

ISSN: 2262-8339

\section{Publisher}

Réseau interuniversitaire d'étude des littératures contemporaines du Río de la Plata

\section{Electronic reference}

Edgardo Cozarinsky, «El dandismo y la elegancia como invisibilidad de la apariencia », Cuadernos LIRICO [En línea], 16 | 2017, Puesto en línea el 23 septiembre 2017, consultado el 19 abril 2019. URL : http:// journals.openedition.org/lirico/3577; DOI : 10.4000/lirico.3577

This text was automatically generated on 19 April 2019

\section{(c) $(1) \odot$}

Cuadernos LIRICO está distribuido bajo una Licencia Creative Commons Atribución-NoComercialSinDerivar 4.0 Internacional. 


\title{
El dandismo y la elegancia como invisibilidad de la apariencia
}

\author{
Edgardo Cozarinsky
}

Este texto fue publicado originalmente como prólogo a William Hazlitt, William M. Thackeray, Oscar Wilde, Virginia Woolf, Gentlemen. Los mejores escritos del dandismo inglés (Buenos Aires, Mar Dulce Editora, 2015). Agradecemos a Edgardo Cozarinsky y Damián Tabarovsky su autorización para reproducirlo.

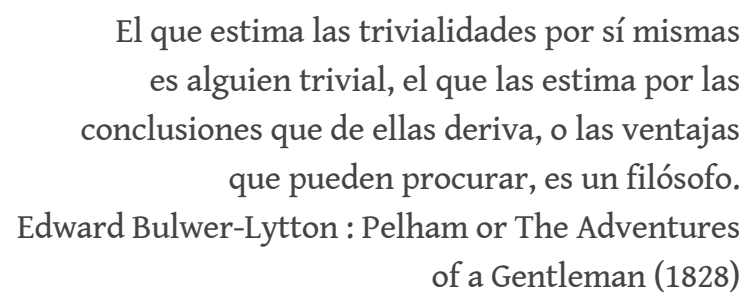

El idioma inglés conoció, a partir de ese mismo siglo XVIII que vio surgir la "corporación de los dandis", algunas reflexiones excéntricas sobre la ropa. Borges traza un arco entre $A$ Tale of a Tub (1713) del irlandés Jonathan Swift y Sartor Resartus (1834) del escocés Thomas Carlyle en su "Nota preliminar" a la edición de este último libro (Emecé, 1945).

2 Disimiles y distantes, ajenos ambos a la vida de salón londinense, Swift y Carlyle observaron con escepticismo y mordacidad la puesta en escena social a través de la vestimenta. "Determinadas pieles de armiño, colocadas de cierto modo, forman lo que se ha dado en llamar un juez, así como una justa combinación de raso negro y tejido Cambray se llama un obispo" (J. Swift, A Tale of a Tub, II).

3 El título latino del inclasificable Sartor Resartus, texto que hoy sería definido como "metaficción", puede traducirse por "Sastre remendado"; su subtítulo es "vida y opiniones de Herr Teufelsdrökh", pensador ficticio cuyo nombre completo es Diógenes Teufelsdrökh, es decir hijo de Dios, mierda del Diablo. En su disquisición sobre la relación del individuo y la sociedad con la vestimenta, el autor adopta burlonamente un discurso filosófico. Un capítulo entero, el décimo del tercer libro, lo dedica a la "corporación de los dandis". 
4 "Un dandi", declara, "es un hombre que viste ropa, un hombre cuyo comercio, oficio y existencia consiste en vestir ropa. Toda facultad de su alma, de su espíritu, de sus bienes y persona están consagrados heroicamente a vestirse sabiamente y bien." Después de asimilar a una disciplina monástica la dedicación de estos a su apariencia, Carlyle finge asumir su defensa : "por todo este perpetuo martirio [...] ¿qué exige en cambio un dandi ? Simplemente, puede decirse, que reconozcamos su existencia ; que admitamos que es un objetivo vivo; o al menos, a falta de eso, que es un objeto visual, que puede reflejar los rayos de la luz. No solicita vuestra plata o vuestro oro [...] sino una simple mirada de vuestros ojos: miradlo solamente y lo haréis feliz. ¿No podemos clamar vergüenza ante un mundo ingrato que rehúsa hasta ese modesto favor, que desperdicia sus facultades ópticas en cocodrilos disecados y hermanos siameses y que para una prodigiosa maravilla de las maravillas domésticas - un dandi vivo- no tiene sino una mirada de indiferencia, de desprecio apenas disimulado? Ningún zoólogo lo clasifica entre los mamíferos, ningún anatomista lo diseca con cuidado: ¿hemos visto alguna vez en nuestros museos una preparación, un ejemplar de dandi conservado en alcohol ?".

5 A Max Beerbohm le hizo gracia que un hombre tan descuidado en el vestir como Carlyle dedicara un tratado filosófico a la ropa.

***

6 El dandismo surgió antes del Beau Brummell, su figura emblemática, pero alcanzó su cenit en ese momento en que la aristocracia inglesa, sacudida por la Revolución Francesa, siente curiosidad por el mundo nuevo que asoma en el continente ; su estructura no se quiebra pero su forma pierde rigidez en la performance social. (Aun hoy, ingleses de toda clase social se refieren a Europa como "el continente", algo próximo pero sustancialmente ajeno.) En esa tierra de excéntricos, el dandismo floreció con brío. Exportado a Francia, en cambio, se impuso como pronunciamiento aristocratizante, antirrepublicano : de Baudelaire a Barbey d'Aurevilly fue teorizado en clave más nihilista que nostálgica de un ancien régime, que estos autores veían restaurado en desteñida monarquía pequeñoburguesa. De allí la anglofilia de varias generaciones de artistas y escritores franceses, su gusto adquirido por la $\mathrm{h}$ aspirada en el habla, signo de una elección no solo estética. Con la distancia de un siglo, Camus llegaría a ver al dandi como "la creación más original" del romanticismo, "desafío a la ley moral y divina".

7 "Recuerde siempre: uno se viste para fascinar a los demás, no a sí mismo" (BulwerLytton). Si pensamos en el clavel teñido de verde en el ojal de Oscar Wilde, o en los chalecos bordados y profusos anillos de Manuel Mujica Lainez, nos referimos a predicados del personaje público, prescindible marginalia de la obra escrita; incurren en una teatralidad que sería lo opuesto del dandismo cultivado por Brummell.

8 Se ha señalado que Brummell llevó a los salones una traducción de la ropa rural, la del terrateniente que dedica más tiempo a supervisar su propiedad que a mundanidades, y que el efecto de este solecismo deliberado resultó "revolucionario". Se trataba, sin embargo, de una forma de coquetería: ningún country squire consagraba horas a su atuendo. El cuarto de vestir de Brummell fue comparado con el taller de un artista : allí componía diariamente el elaborado retrato de sí mismo que iba a exponer por unas pocas horas en los salones de Londres. Sus famosos corbatones altísimos y almidonados eran probados y desechados si revelaban un pliegue fuera de lugar.

9 Sobre este ascetismo del personaje, Max Beerbohm es lapidario: "Los innumerables anillos de D’Orsay, las muchas pequeñas cadenas de oro 'más delgadas que telarañas' que 
Disraeli insinuaba de un bolsillo a otro de su chaleco, le hubiesen parecidos vulgares a Mr. Brummell [...]. En ciertas congruencias de tela oscura, en la rígida perfección de sus camisas, en la simetría de guante y mano, yacía el secreto de los milagros de $\mathrm{Mr}$. Brummell. Siempre fue el más económico, el más escrupuloso en sus medios".

10 Anthony Trollope resumió una idea que iba a conocer larga posteridad: "Opino que el caballero mejor vestido es aquel cuya vestimenta nadie nota" ("I hold that gentleman to be the best dressed whose dress no one observes"). La elegancia como invisibilidad de la apariencia : disciplina exigente, a menudo costosa, que pocos se deciden a cultivar. En la segunda mitad del siglo XX, Michel Leiris hacía lavar las camisas recién compradas para que no parecieran nuevas; el más distinguido diplomático argentino, Lucio García del Solar, solía vestir ropa nada flamante, que por esta misma razón permitía resaltar el corte impecable y la calidad de la tela.

11 El rigor vestimentario de Brummell tenía por meta una sutileza que solo miradas muy adiestradas pudieran percibir. Este refinamiento, opuesto a lo llamativo, elegía a sus espectadores. Por otra parte, compensaba esta discreción con la práctica de la insolencia, una mezcla de indiferencia y desenvoltura que corresponden a ese "aristocrático gusto por disgustar" que definió Stendhal. ¿Una forma, acaso, de resaltar el origen de clase media -algo a lo que es sensible Woolf, que se reconoce en ese nicho del clasismo británico- de un individuo aceptado entre aristócratas por su gracia, por esa mezcla inefable de talentos mundanos apreciada en los salones más exclusivos, no solo en la amistad del Regente? Las anécdotas legadas por Brummell lo ilustran en abundancia. Hazlitt y Beerbohm recogen algunas.

12 Una noche, al salir de su casa, le pregunta al cochero dónde le toca cenar ese día. A un arribista que buscaba frecuentarlo, finalmente le acepta una invitación "con la condición de que guardase el secreto". En una ocasión, sentado a la mesa entre dos nobles, llama a su lacayo, de pie a sus espaldas, para preguntarle sin bajar la voz quiénes son las personas que tiene a su derecha y a su izquierda. En su juventud, Brummell había pasado brevemente por el $10^{\circ}$ Regimiento de Húsares; al día siguiente de que su superior le pidiera que se abstuviese de participar en un desfile -el joven oficial rehusaba asimilarse a los demás uniformados y elegía distinguirse con una capa de seda azul-, el futuro héroe de los salones aristocráticos solicitó su baja del arma.

***

13 Thackeray fue testigo, aun cronista, del ocaso del dandi en su concepción "brummelliana". Cuando abordó el tema en ensayos y novelas, el Beau, cubierto de deudas e insolvente, ya había muerto en Francia, en 1840, exiliado para eludir la prisión en la poco radiante ciudad de Caën, donde había sobrevivido gracias a invitaciones menos suntuosas que las recibidas en su hora de gloria ; peor aún : calvo, adiposo, sifilítico, senil.

14 Pendennis, o para citar completo el título de la primera edición, The History of Pendennis: His Fortunes and Misfortunes, His Friends and His Greatest Enemy, fue la novela de Thackeray que siguió inmediatamente a su más famosa : Vanity Fair (1848). Escrita entre 1848 y 1850, esta historia del provinciano que llega a Londres con la intención de hacerse un lugar en la "feria de vanidades" de la gran ciudad, primo inglés del Rastignac de Balzac pero sin su ambigüedad sexual, propone una visión particular del dandismo, tema que evidentemente trabajaba el autor, entre fascinación y rechazo, ya que lo había abordado en obras contemporáneas : el ensayo "Men and Coats" (1841), The Snobs of England (1846-1847) y Mr Brown's Letters to a Young Man About Town (1849). 
15 Thackeray no censuraba el dandismo de Brummell, cuyo estilo consideraba "viril". Apreciaba su respeto por lo natural antes que el culto del artificio, propio de la imagen del dandi más difundida por periodistas e ilustradores satíricos de su tiempo ; sobre todo, lo elogiaba por la observancia del aseo, algo entonces poco frecuente. Brummell, según Thackeray, exigía del sastre respeto por la forma del cuerpo, sin aditamentos que compensaran sus defectos, así como prefería tonos oscuros y sobrios para sus chaquetas. El joven Pendennis, su personaje, se convierte en un dandi a través de la vestimenta y los modales, pero no renuncia a la austeridad y sencillez en la proyección pública de su carácter ; permanece lejos de la representación teatral de un personaje construido, como en Byron, Bulwer-Lytton o Disraeli.

16 Thackeray sabía de qué hablaba: había frecuentado a personajes mundanos que resumían ese culto exagerado de la teatralidad, como el conde D'Orsay, ejemplo notorio de afectaciones en los salones de su época. Hacia 1860, diez años después de compuesta Pendennis, cuando "la corporación de los dandis" había sido archivada en la crónica de una época clausurada, vio con estupor entrar en una taberna a un anciano que correspondía exactamente a la descripción del capitán Costigan hecha en la novela. Azorado ante la encarnación de su personaje ficticio, lo invitó a beber y así se enteró de que se trataba de un ex capitán de granaderos, ocasional parlamentario por Stafford, único sobreviviente de un mundo social difunto, bailes con duquesas, noches enteras en casas de juego, alguien "que había envidiado las espléndidas chaquetas y milagrosas corbatas del Beau Brummell" y por haberlo visitado no consideraba inferior a esa elegancia la de muebles y objetos entre los que había vivido el Beau. Era, concluye Thackeray, "el último de los dandis de la Regencia de Jorge IV".

17 Como en todos los tiempos, reconocemos que nos fue dado vivir un momento irrecuperable. Como en todos los tiempos, una generación venidera resucitará, bajo nombres cambiantes, personajes y fastos parecidos, y algún día también sentirá que fueron los últimos.

$* * *$

18 Existe también una forma de dandismo opuesta a esa práctica de la insolencia en busca del desafío social. Se trata de una especie de elegancia moral, un dandismo que el espectador percibe -me arriesgo a la contradictio in adjecto- como espontáneo. Está basado en la afabilidad. Lucio V. Mansilla parecía tan cómodo en compañía de un cacique ranquel como en la de Robert de Montesquiou, el empolvado modelo del Charlus de Proust. Adolfo Bioy Casares solía agradecer a quien aceptaba sus invitaciones. En contraste con la displicente arrogancia de parvenus como Evelyn Waugh o Philippe Jullian, este dandi prefiere practicar el arte de poner cómodo al desigual, aun incurriendo en la autodenigración.

19 Me permito una anécdota personal. En mi primera juventud, en mi también primera visita a Londres, me invitó a almorzar en un club de St. James un desconocido, amigo del que había sido mi profesor de inglés en Buenos Aires (eran años en que un viajero debutante aún llevaba "cartas de presentación"). Agasajado con sherry durante la conversación previa en la biblioteca, con claret durante el almuerzo y cognac en el café, minutos más tarde debí acudir al baño de ese distinguido reducto para vomitar con entusiasmo. A varios metros de distancia, desde un mingitorio, un caballero intentó sin duda aliviar mi incomodidad fingiendo que no advertía mi estruendosa deposición y empezó a compartir en voz alta sus observaciones : "Qué sensato del club que conserve las instalaciones sin pretender modernizarlas. Todo esto es mármol, auténtico mármol, nada 
de estuco"; luego, bajando la vista : "En comparación, mi pobre pito luce bastante gastado (by comparison, my poor cock looks rather shabby)".

$* * *$

20 La sociedad de masas vio surgir formas nuevas de dandismo, inevitablemente opuestas a la tradicional, aun inversión de su norma. Lejos de una vida social centrada en salones y actuada por y para un público selecto, la puesta en escena de la excentricidad en el vestir y la conducta adoptó formas rara vez individuales, más a menudo tribales, necesariamente urbanas, agresivas hasta que llega el momento, nunca lejano, en que las recupera el omnívoro mercado.

21 En este sentido fueron cultores de una forma aggiornata de dandismo Andy Warhol y su tropa de The Factory tanto como los cultores de la estética punk en sus diversas declinaciones, también performers como David Bowie y Quentin Crisp : dependientes todos sin excepción de los medios de comunicación masivos. La autocreación actual del dandi puede tener como punto de partida un defecto: "mi estricto uniforme", como lo llama Mario Bellatin, depende menos de la cabeza rapada o de la túnica negra combinada con pantalones y botas del mismo color, que del antebrazo ausente desde su nacimiento, que solía compensar con una prótesis metálica dotada de pinzas; la exquisita cortesía y modestia del escritor actúan como antídoto irónico de lo que ese "uniforme" podía tener de provocador. En un extremo opuesto, no pueden asimilarse al dandismo las payasadas de Salvador Dalí, que pertenecían llanamente al orden de la vulgaridad.

22 En literatura, la Argentina conoció a principios de los años 70 del siglo pasado un momento de (lo que sus autores acaso no habrían reconocido como) dandismo. Mientras una militancia armada iba afirmándose en la sociedad, y se preparaba su represión, el carácter revulsivo de textos como El frasquito de Luis Gusmán y El fiord de Osvaldo Lamborghini corresponde a la voluntad de excepción que estuvo en el origen del dandismo histórico.

23 A principios del siglo XXI, en Chile, muchos vástagos de familias cuyo apellido tradicional aun conserva una vigencia que sus homólogos argentinos perdieron, practican lo que un observador ha llamado "abajismo". Para distinguirse de las fortunas recientes, fruto de la economía del pinochetismo y sus secuelas, de sus criaturas que renuevan regularmente el guardarropa en shopping malls de Miami, el "abajista" luce, por ejemplo, un sweater de cashmere inglés con agujeros polilla, un saco de puro lino raído en los codos.

24 Es probable que cierto impulso al dandismo, en manifestaciones que serían irreconocibles para sus cultores originales, no haya claudicado y en un futuro (que ya asoma) conozca reencarnaciones imprevisibles mientras haya individuos, aun grupos que busquen distinguirse de la sociedad donde actúan. Miremos a nuestro alrededor porteño : el rockero suburbano, que gasta dinero que no tiene en ropa auténticamente vintage, el judío de clase media que decidió nunca psicoanalizarse : estas criaturas pasan a nuestro lado. Sin estrépito, lejos de los salones londinenses donde Brummell lució sus minuciosas toilettes, anuncian un avatar posible para el dandismo. 